\title{
BEHAVIOUR OF PRE-STRESSED HIGH STRENGTH CONCRETE SLEEPERS SUBJECTED TO DYNAMIC LOADS
}

\author{
Taherinezhad Javad ${ }^{1, *}$, Priyan Mendis ${ }^{1}$, Tuan Ngo ${ }^{1}$ and Massoud Sofi ${ }^{1}$ \\ ${ }^{1}$ Department of Infrastructure Engineering, the University of Melbourne, Parkville, VIC, Australia, 3010. \\ *Email: jtaherin@gmail.com
}

\begin{abstract}
As part of ballasted railway track, pre-stressed concrete sleepers (PCSs) play an essential role in track response, performance and safety. PCSs are subjected to dynamic loads which are often high magnitude and low duration. The characteristics of dynamic loads, the interactions between track components and the dynamic responses of PCSs under dynamic loads have been vastly investigated throughout past decades and continue to be a subject of interest to the railway industry.. Mechanical behaviours of PCSs such as dynamic response and failure mechanisms are important to meet the structural and durability requirements of railway sleepers. However, the influence of high performance concrete (HPC) mechanical properties on behaviour of PCSs is currently lacking. This paper presents a finite element model developed as a part of a broader investigation undertaken at the University of Melbourne. Finite element modelling package LS-DYNA has been used to represent a sleeper in a simulated track condition. The model is validated based on published experimental information. Different grades of high strength concrete (HSC) have been investigated. Mechanical properties such as compressive strength, tensile strengths, fracture energy and elastic modulus are considered.. The results show that the using higher concrete grade in sleeper leads to a larger bending moment under the same dynamic load. This confirms the inadequacy of current design approach for PCSs.
\end{abstract}

\section{KEYWORDS}

Concrete sleeper, finite element modelling, LS-DYNA, dynamic loads, high performance concrete

\section{INTRODUCTION}

Railway is known as the best and the safest transportation mode for both passengers and merchandise across the world. Conventional track or ballasted track is still used in a large number of new tracks, even those made for high speed trains or heavy-haul trains. Ballasted tracks consist of two main parts, substructure (including ballast, sub-ballast and formation layer) and superstructure (including rail, fastening system and sleeper), as shown in Figure 1. As an essential member of ballasted track, sleepers play a major role in track performance and safety. Their main duty is support the rails, distribute the loads from the rails to the ballast, maintain the track gauge and tolerate the movements of the rails. Although, a few types of sleepers, such as timber and steel, have been utilised since establishment of the railways, pre-stressed concrete sleepers (PCSs) are the most popular type at the present time.

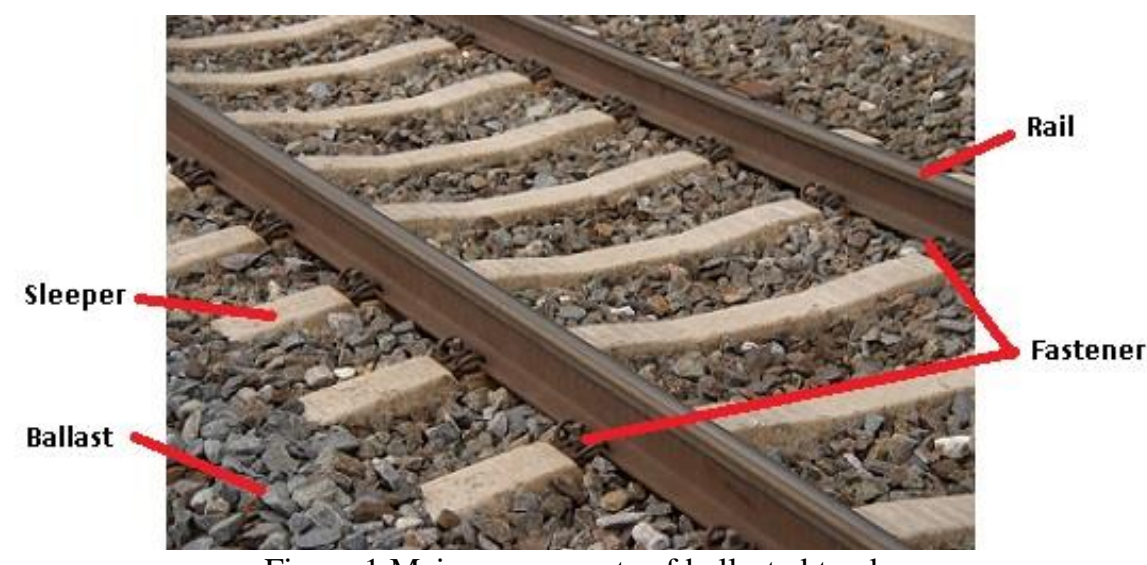

Figure 1 Main components of ballasted track

While the static wheel load of trains varies between $25 \mathrm{kN}$ to $200 \mathrm{kN}$ depending on the train type and function, the dynamic contact force between wheel and rail-head can reach over $750 \mathrm{kN}$. These high magnitude dynamic 
loads have duration in the range of 1 to $12 \mathrm{~ms}$ and are generated due to irregularities at the wheel surface, abnormalities at the head of rail or even discontinuity in the support layer (Remennikov and Kaewunruen, 2008). The shape of the dynamic loads in time domain and their magnitude mostly depends on the kind of causes and rolling speed. These loads transfer to the sleeper via the fastening systems.

PCSs are expected to withstand the high magnitude loads and harsh environments. These loads can cause premature damages in PCSs mostly in the form of cracks (Van Dyk et al., 2012) which, in turn, facilitate penetration of water and corrosive ions, particularly chloride ions. Corrosion of the strands under the influence of chloride ions is known as a significant factor that leads to deterioration of sleepers and shortens their lifespan (Mohammadzadeh and Vahabi, 2011). In spite of the premature damage, researchers believe that there is a huge amount of untapped strength in PCSs (Remennikov et al., et al., 2007 and Leong and Murray, 2008). A controversial issue of premature damage and untapped strength is often attributed to conservativeness of static analysis and an allowable-stress design approach of PCSs which is prescribed by standard codes (Remennikov et al., 2007, Nairn and Stevens, 2010 and Murray and Bian, 2012).

For better understanding the behaviour of PCSs and address the unresolved problems which considerably shorten their service life, extensive research has been undertaken. Reviewing the literature, Taherinezhad et al, (2013) has indicated that the research works have shed some lights on the behaviour of PCSs and their interactions with other components of the track. Nevertheless, the material performance is still a subject of interest to the railway industry. High performance concrete (HPC) is believed as an appropriate solution to the issue. Very recently, some aspects of a few high performance concrete sleepers have been investigated (Hwang et al., 2011, Li et al., 2012 and Ramezanianpour et al.,2013). However, investigating the behaviour of HPC sleepers under the dynamic loads is still lacking.

The main purpose of this article is to report on the mechanical behaviour of high strength concrete (HSC) sleepers subjected to dynamic loads, as a part of a broader investigation undertaken at the University of Melbourne. The aim of the investigation is to establish the material necessities of the concrete sleepers in order to satisfy the structural and durability requirements. In the following sections, the methodology including available experimental study and the modelling approach for finite element analysis is reported.

\section{METHODOLOGY}

To investigate the mechanical behaviour of high performance concrete sleepers a finite element model has been developed using ANSYS LS-DYNA. The model has been calibrated based on available results of a comprehensive experimental work that had been conducted at the University of Wollongong Australia by Kaewunruen (2007) and colleague. A parametric study has been conducted to analyse the influence of concrete mechanical properties on the behaviour of pre-stressed concrete sleeper subjected to dynamic loads. This section is divided into two sub-sections. The first sub-section will introduce the experiments. The model and validation is reported it he second sub-section.

\section{Experimental Overview}

To study some aspects of mechanical behaviour of PCSs, Kaewunruen and Remennikov (2009, 2010 and 2011) utilised a high capacity impact test apparatus. The core of the test rig is a falling mass with a maximum drop height of $6 \mathrm{~m}$. The weight of projectile was set as $5.81 \mathrm{kN}(592 \mathrm{~kg})$, and the drop heights varies to generate different magnitude of impact load at rail head. The impact loads were recorded by the dynamic load cell which installed at the rail head and connected to a computer. A high speed camera has been used to obtain the efficiency of drop weight through the calibration tests. Using the test rig the mechanical responses such as impact behaviour, impact capacity, impact fatigue, progressive failure and crack propagation of few PCSs, which are widely used in Australia, have been studied.

Using the actual ballast bed in the experimental work can cause difficulties in controlling boundary conditions and rearranging the test setup after multiple high magnitude impact loads. On the other hand, Australian Standard AS-1085.19 has adopted the alternative ballast for a specific use (AS-1085.19-2013, 2003). It states "the support shall permit a vertical deflection in the range of $0.1 \mathrm{~mm} 0.5 \mathrm{~mm}$ (inclusive) when a sleeper supported on it is subjected to an increase in static load from $50 \mathrm{kN}$ to $60 \mathrm{kN}$ at one rail seat". Kaewunruen and Remennikov (2008) tested a variety of rubber material to simulate the ballast layer. Finally, they found that a combination of six layers of conveying belt provides satisfactory results and meets the stiffness requirement of alternative support prescribed in the Australian Standard. 
To ensure realistic simulation of an actual track conditions using this approach, the relationship between impact load and dynamic bending moment at the rail seat has been investigated experimentally and compared with those of D-TRACK finite element model which was developed by Cai (1992) (as cited by Kaewunruen, 2007). The validity and capability of D-TRACK for simulation of track behaviour were investigated through 2 benchmark programs by Steffens (2005) and Leong (2007). A comparison of the results confirms the suitability of experimental test approach to model the actual impact loading of sleepers.

Although Kaewunruen and Remennikov (2009, 2010 and 2011) have examined sleepers with different lengths, cross sections and material properties in their study through the last decade, their final work has been considered for the current study. The selected sleeper represents a heavy-duty sleeper with total length of $2.80 \mathrm{~m}$ and gauge length of $1.60 \mathrm{~m}$. The unconfined compression strength and mass density of concrete were $55 \mathrm{MPa}$ and 2350 $\mathrm{kg} / \mathrm{m}^{3}$, respectively. 22 pre-tensioning strands were the high strength with rupture strength of $1860 \mathrm{MPa}$ and diameter of $5.03 \mathrm{~mm}$. The initial strain of strands due to pre-tensioning was about $6.70 \mathrm{~mm} / \mathrm{m}$. Figure 2 depicts the dimensions of the sleeper cross section at the rail seat and midspan plus locations of 22 pre-stressing tendons.

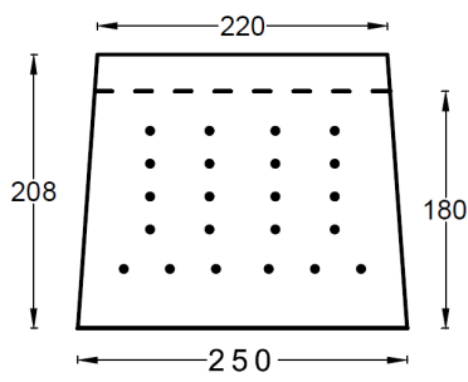

Figure 2 Dimensions of sleeper cross section at the rail seat and midspan, mm (Kaewunruen and Remennikov, 2011)

\section{The Finite Element Modelling Approach}

LS-DYNA has been used to develop a finite element model for better understanding of mechanical and cracking behaviour of PCSs and investigating the influence of concrete properties on sleeper behaviour such as stress distribution, cracking and bending moment. LS-DYNA is an advanced non-linear multi-physics simulation package to solve many complex and real world problems by using a time step history of explicit scheme. It has significant capability in simulating dynamic and high-rate loading such as falling-mass impact and blast shock. Although LS-DYNA is basically developed to analyse various types of structures and members subjected to dynamic loads, it provides three different methods to include static preloading: (a) explicit dynamic relaxation; (b) quasi-static transient analysis with mass damping; and c) implicit static analysis. Besides, LS-DYNA has a comprehensive library of material models which are capable of capturing the most key aspects of material behaviour (Hallquist, 2006).

There are about 30 material models available in LS-DYNA to represent geo-materials, such as soil, rock and concrete. However, for realistic predicting of concrete behaviour subjected to a triaxial state of stress, the constitutive model needs to simulate main features of material such as pressure-hardening, strain-softening, strain rate enhancement and crack propagation. Six constitutive models have been developed specifically for concrete material and implemented in LS-DYNA, including MAT072, MAT084-85, MAT111, MAT159, MAT172 and MAT272 (LSTC, 2009). While all of these models need more than 20 input parameters to capture key features of concrete, four models including MAT072R3, MAT084, MAT159 and MAT272 exhibit an automatic input capability to generate the data for model parameters (Brannon and Leelavanichkul, 2009). The first three models have been well documented and validated by a large number of research works since implemented in LS-DYNA. The suitability of these three models for analyzing PCSs under dynamic loading was investigated (Taherinezhad and et al., 2015). It has been demonstrated that MAT084 (Winfrith concrete model) simulates the behaviour of PCSs more suitable than those anticipated by the others in this case.

MAT084, the Winfrith concrete model, was implemented into LS-DYNA in 1991. The model was developed in 1980s, intended in analysing reinforced concrete structures under impact loading. The model provides a basic plasticity model includes strain softening in tension, omission of material dilation, optional strain rate enhancement and optional inclusion of smeared reinforcement. Furthermore, the model allows up to three orthogonal crack planes per element and cracks can be visualized via a post-processing interface such as LSPREPOST (Schwer, 2011). In the case of automatic parameter generation, this model needs 7 mechanical 
properties including density tangent modulus of elasticity, Poisson's ratio, uniaxial compressive strength, uniaxial tensile strength, fracture energy and maximum size of the aggregate.

An elaborated finite element model of the test as introduced in previous section has been developed. The model consists of a full scale concrete sleeper, pre-stressing tendons, two segments of rails, fastening system, simulated supporting environment, falling-mass and supporting base. Figure 3 indicates the complete finite element model. As the stress distribution in fastening system and its interactions with other parts are not the aim of this study, it has been simplified in geometry. However, the pre-loading to fix the rail to the sleeper has been simulated. The model considers all tendons as TRUSS elements and the fastening bolts and the fixing bolts (bolts used to fix the sleeper to the test rig) as BEAM elements. Further, all other parts are made of hexahedral SOLID elements. It contains 44 parts, 3'098 Truss elements, 54 BEAM elements, 141'474 SOLID elements and 180'088 nodes.

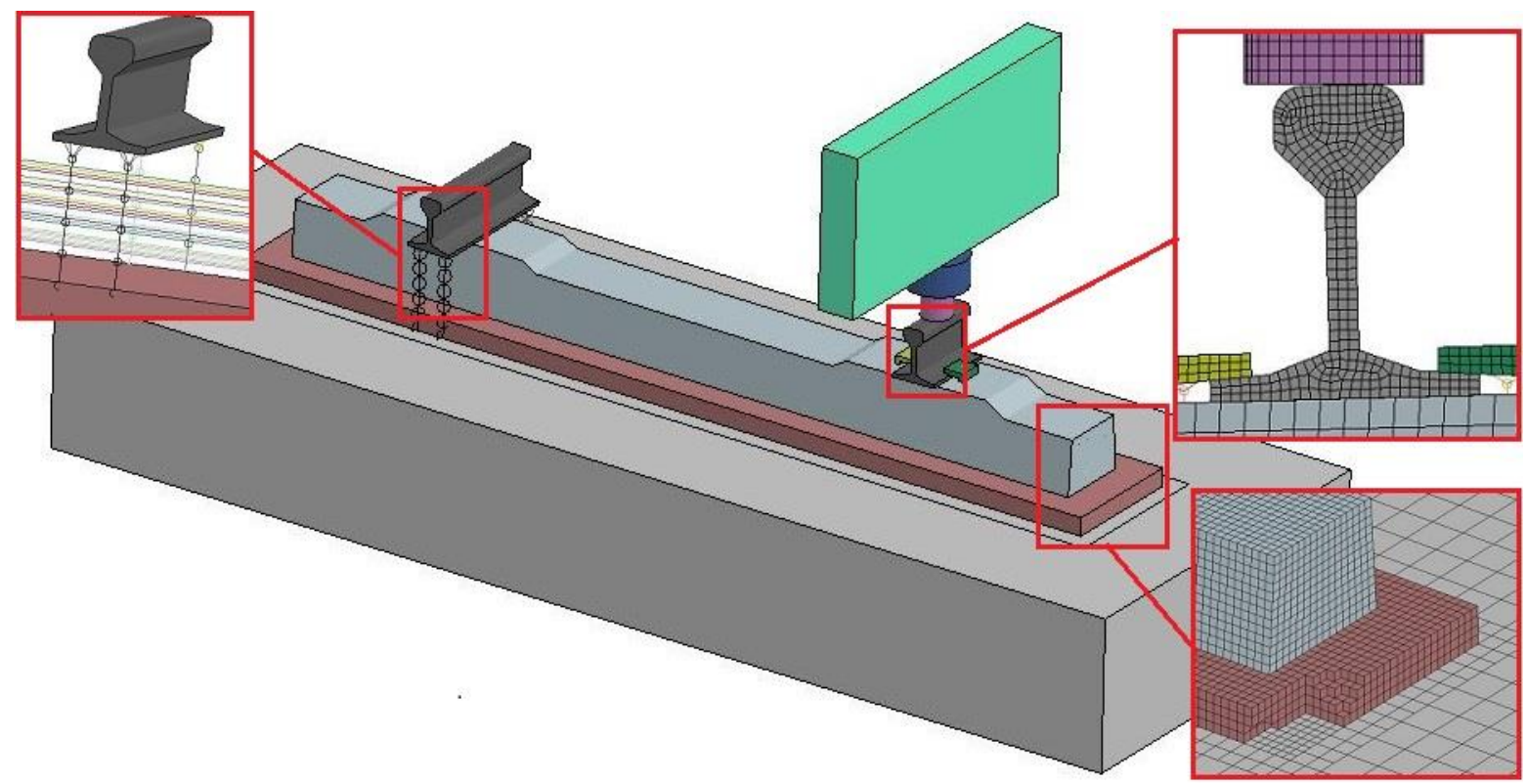

Figure 3 Schematic view of entire finite element model and few details of meshed parts

The analysis in this study is divided into two phases. In the first phase, dynamic relaxation is utilised to apply pre-loads including tendons pre-tensioning, the fasteners preload to connect the rail to the sleeper and pretensioning of bolts that used to fix the sleeper to the supporting environment. After completion of dynamic relaxation phase, the transient phase starts to generate the dynamic load by defining an initial velocity for the falling mass. The dynamic load is generated at contact between the nose of impactor and the head of rail then transfers to the sleeper through the rail.

\section{Model Validation}

Validation of the model is an important consideration in a finite element model to ensure a satisfactory representation of the reality. Thus, the newly developed finite element model in this study was calibrated and validated based on aforesaid experimental works. The contact force between the impactor and rail was used to calibrate the model. Figure 4 shows two samples of calibration of the model based on contact force due to 600 $\mathrm{mm}$ and $400 \mathrm{~mm}$ drop heights. To validate the model in the preloading phase, a computer program has been developed based on design approach of Australian Standard. The program calculates the stresses at the critical locations of sleeper including top and bottom of the rail seat and midspan. The stresses at these locations were also extracted from the finite element model. The results show good agreement between the analytical model and numerical model, see Table 1 . To validate the model in the transient phase, the maximum bending moment at the rail seat has been compared by that measured during the experiments by Kaewunruen and Remennikov (2009). Figure 5 indicates relationship between dynamic force generated at the rail head and the bending moment of sleeper at the rail seat. The results show good correlation with a trend line which is suggested based on the test results, especially, those due to drop height of $600 \mathrm{~mm}$ which is used for the rest of analysis in this paper. This drop height corresponds with velocity of $3.43 \mathrm{~m} / \mathrm{s}$ at the moment of contact. In this case the dynamic load at the contact between the impactor nose and rail head can reach $880 \mathrm{kN}$, see Figure 4. 

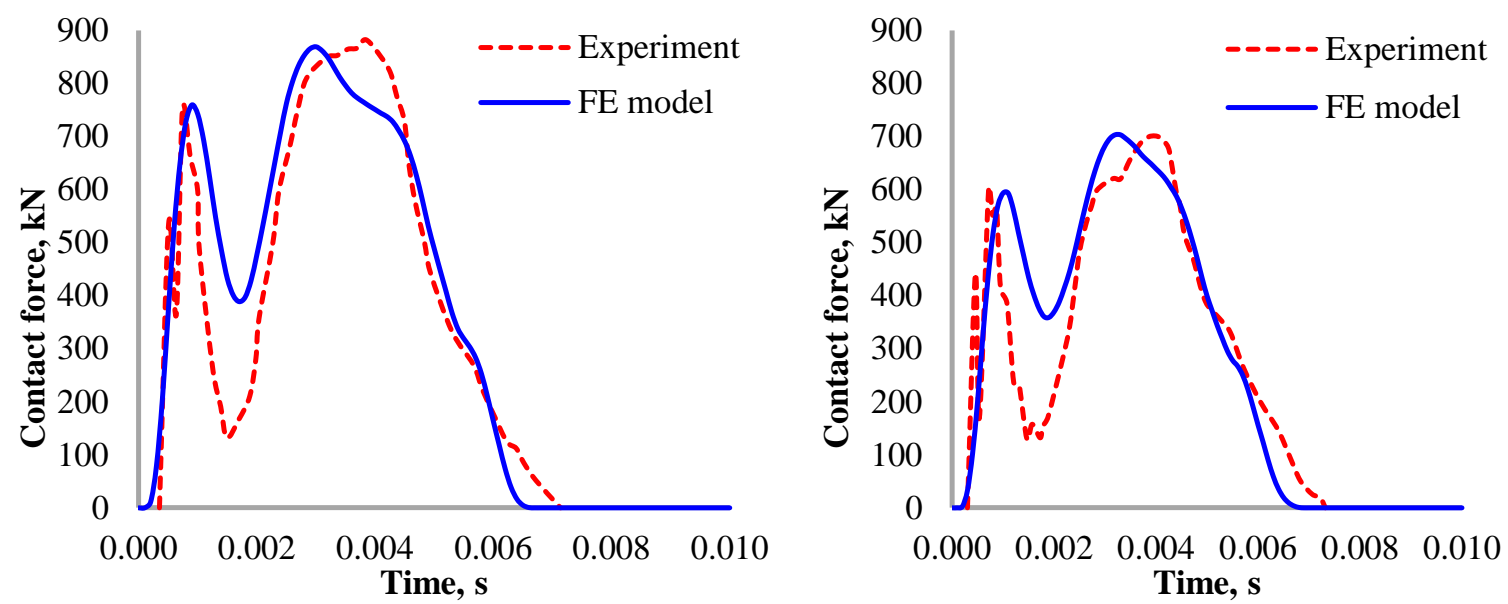

Figure 4 Time history of contact force between impactor and rail head due to drop heights of $600 \mathrm{~mm}$ (left) and $400 \mathrm{~mm}$ (right), the experimental results adapted from (Kaewunruen and Remennikov, 2009)

Table 1 Comparison of pre-tensioning stress at critical zones of the sleeper

\begin{tabular}{lcccccc}
\hline \multirow{2}{*}{ Location } & \multicolumn{3}{c}{ Midspan } & \multicolumn{3}{c}{ Rail seat } \\
\cline { 2 - 7 } & $\begin{array}{c}\text { Analytical } \\
(\mathrm{MPa})\end{array}$ & $\begin{array}{c}\text { FEM } \\
(\mathrm{MPa})\end{array}$ & $\begin{array}{c}\text { Difference } \\
(\%)\end{array}$ & $\begin{array}{c}\text { Analytical } \\
(\mathrm{MPa})\end{array}$ & $\begin{array}{c}\text { FEM } \\
(\mathrm{MPa})\end{array}$ & $\begin{array}{c}\text { Difference } \\
(\%)\end{array}$ \\
\hline Top & 15.07 & 14.31 & -5.0 & 8.40 & 7.65 & -8.93 \\
\hline Bottom & 11.03 & 11.74 & +6.4 & 14.16 & 14.32 & +1.1 \\
\hline
\end{tabular}

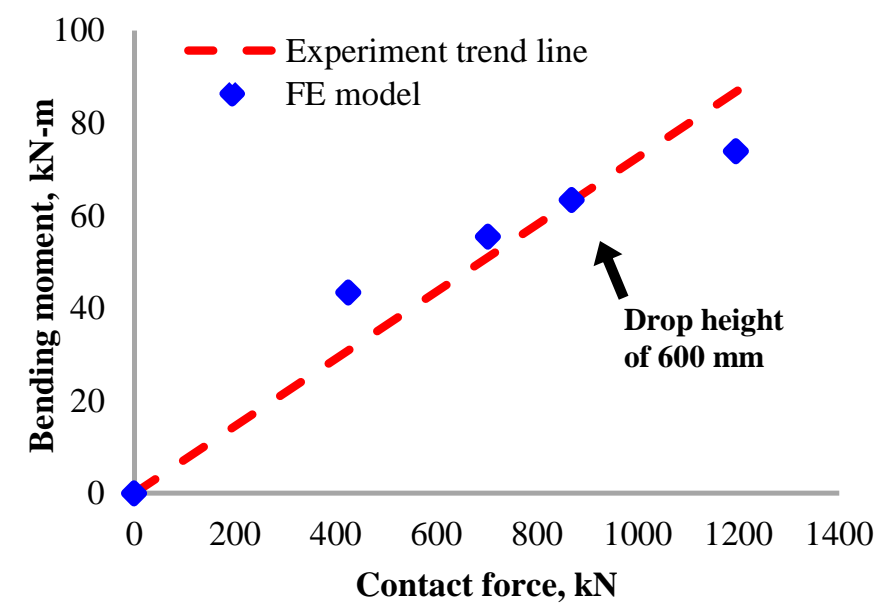

Figure 5 Ralationship between bending moment at the rail seat and contact load at the rail head, the experimental results adapted from (Kaewunruen and Remennikov, 2009)

\section{ANALYSIS}

In order to investigate the effects of concrete strength on sleeper behaviour, a few grades of high strength concretes (HSC) including C70, C85 and C99, have been investigated under dynamic load. The mechanical properties of each grade have been estimated based on standard codes and available literature. The contact force, bending moment at the rail seat and midspan, stresses at rail seat and concrete cracking are studied.

The relationship between characteristic compressive strength $\left(f_{c}^{\prime}\right)$ and the other mechanical properties of concrete have been empirically formulated and published in Standard Guidelines and in the literature (AS3600, 2009; CEP-FIP, 1993; Mendis et al., 1997; Mendis, 2001 and Keru, 2001). CEB-FIP Model Code 1990 (1993) recommended equations for all mechanical properties including uniaxial tensile strength $\left(f_{c t}^{\prime}\right)$, fracture energy $\left(G_{F}\right)$ and modulus of elasticity $\left(E_{c}\right)$, that we need in this study:

$$
\begin{aligned}
& f_{c t}^{\prime}=0.30{f_{c}^{\prime}}^{2 / 3} \\
& E_{c}=10^{4}{f_{c}^{\prime 1 / 3}}^{1 / 3}
\end{aligned}
$$




$$
G_{F}=a_{d}\left(f_{c}^{\prime}+8\right)^{0.7}
$$

Where $f_{c}^{\prime}$ : the characteristic compressive strength, $f_{c t}^{\prime}$ : characteristic tensile strength, $E_{c}$ : modulus of elasticity, $G_{F}$ : fracture energy and $a_{d}$ : index for the influence of maximum diameter $\left(d_{\max }\right)$ of aggregates and $a_{d}$ is 6 for $d_{\max }$ of $16 \mathrm{~mm}, 10$ for $d_{\max }$ of $32 \mathrm{~mm}$. In this article, $d_{\max }$ is $19 \mathrm{~mm}$, so $a_{d}$ is given the value of 6.75 . The predicted values of $E_{c}$ using equation (2) are in very good agreement with those predicted by an equation recommended by Mendis et al., (1997) for HSC. However, estimation of $f_{c t}^{\prime}$ using equation (1) is slightly larger than that estimated using the equation suggested by Australian Standard (AS-3600, 2009). It is worth noting that the value of Poisson's ratio (v) has been set to 0.2 according to CEB-FIP (1993) and AS-3600 (2009). Equation (3) overestimates the fracture energy of HSC as Dong and Keru (2001) has demonstrated based on a series of test results. Therefore, 85 percent of those predicted by equation (3) is used in this study. Based on above discussion, the properties of concrete are presented in Table 2.

Table 2 Values of concrete mechanical properties

\begin{tabular}{cccccccc}
\hline $\begin{array}{c}\text { Concrete } \\
\text { grade }\end{array}$ & $\begin{array}{c}\rho \\
\left(\mathrm{kg} / \mathrm{m}^{3}\right)\end{array}$ & $\begin{array}{c}d_{\max } \\
(\mathrm{mm})\end{array}$ & $\begin{array}{c}f_{c}^{\prime} \\
(\mathrm{MPa})\end{array}$ & $\begin{array}{c}f_{c t}^{\prime} \\
(\mathrm{MPa})\end{array}$ & $v$ & $\begin{array}{c}E_{c} \\
(\mathrm{GPa})\end{array}$ & $\begin{array}{c}G_{F c} \\
(\mathrm{~N} / \mathrm{m})\end{array}$ \\
\hline C55 & 2350 & 19 & 55 & 4.4 & 0.2 & 39.7 & 99 \\
C70 & 2370 & 19 & 70 & 5.1 & 0.2 & 42.6 & 117 \\
C85 & 2410 & 19 & 85 & 5.8 & 0.2 & 45.2 & 134 \\
C99 & 2450 & 19 & 99 & 6.5 & 0.2 & 47.4 & 149 \\
\hline
\end{tabular}

\section{RESULTS AND DISCUSSIONS}

This section presents the results of the finite element model which has been developed using LS-DYNA. The model simulates PCSs made of different grades of concrete that subjected to dynamic loads. The load can exceed $880 \mathrm{kN}$. LS-PREPOST interface has been employed to extract the results including contact force, bending moment, stress and cracking behaviour. Table 3 indicates the results for different grades of concrete materials. The results show that the maximum value of contact force at the rail head does not depended on concrete grade.

Table 3 Bending moments and stress due to drop height of $600 \mathrm{~mm}$ for different concrete grades (parentheses show the ratio to the results of grade C55)

\begin{tabular}{cccccc}
\hline \multirow{2}{*}{$\begin{array}{c}\text { Concrete } \\
\text { grade }\end{array}$} & $\begin{array}{c}\text { Maximum } \\
\text { contact force, } \\
(k N)\end{array}$ & \multicolumn{2}{c}{$\begin{array}{c}\text { Maximum bending moment, } \\
(\mathrm{kN}-\mathrm{m})\end{array}$} & \multicolumn{2}{c}{$\begin{array}{c}\text { Maximum stress at the rail seat in } \\
\text { longitudinal direction, }(\mathrm{MPa})\end{array}$} \\
\cline { 3 - 6 } & 884 & Rail Seat & Midspan & Top & Bottom \\
\hline C55 & 886 & $69.3(1.00)$ & $-36.0(1.00)$ & $-94.0(1.00)$ & $5.9(1.00)$ \\
C70 & 889 & $70.9(1.05)$ & $-36.5(1.01)$ & $-107.5(1.14)$ & $6.4(1.08)$ \\
C85 & 885 & $71.6(1.08)$ & $-37.0(1.03)$ & $-111.4(1.18)$ & $7.1(1.20)$ \\
C99 & & & & &
\end{tabular}

While the dynamic load at the rail head is almost constant for different grades of concrete, the bending moment at the rail seat and midspan of the sleeper increase 8 and 5 percent respectively. This increase can be attributed to the more uniformly distribution of loads on the alternative ballast due to larger stiffness of sleeper. Two factors participate in larger stiffness of sleeper made of HSC; (a) the elastic modulus of concrete increases with increasing the compressive strength, and (b) less cracks of concrete at the rail seat. Figure 6 indicates the visible cracks (with minimum crack width of 50 micrometers) at the bottom of rail seat.

A comparison of the maximum stress values ( in Table 3) with the tensile and compressive strength values of concrete presented in Table 2 indicates that the maximum stresses are larger than the strength of concrete. It should be noted that only a limited number of concrete elements experience such large compressive stresses, see Figure 7. These elements located just underneath and are confined by the rail. The increase of compressive strength can be ascribed to strain rate enhancement and confinement effects. MAT084 material model considers the enhancement of concrete compressive strength due to both strain rate effects and confinement effects. In case of tensile stress, strain rate enhancement is the only factor which participates to the higher tensile strength.

Tensile softening is another key feature of concrete which plays a significant role in cracking behaviour of the PCSs. Study of tensile strain and stress variation at the bottom of rail seat indicates that the model properly simulates this behaviour. Figure 8 shows time history of tensile strain and stress at the bottom of rail seat of the 
sleeper (point B, Figure 7) made up of concrete grade C99 under drop height of $600 \mathrm{~mm}$. At the beginning of analysis both strain and stress start to increase proportionally. At time around $0.0007 \mathrm{sec}$ stress reaches its maximum value and suddenly drops to about zero but, strain keeps its upward trend till exceeds strain of 4 $\mathrm{mm} / \mathrm{m}$. However, it should be noted that the curve shape of compressive stress and strain in time domain are similar and the compressive strain fluctuates between $-0.15 \mathrm{~mm} / \mathrm{m}$ and $-1.9 \mathrm{~mm} / \mathrm{m}$.

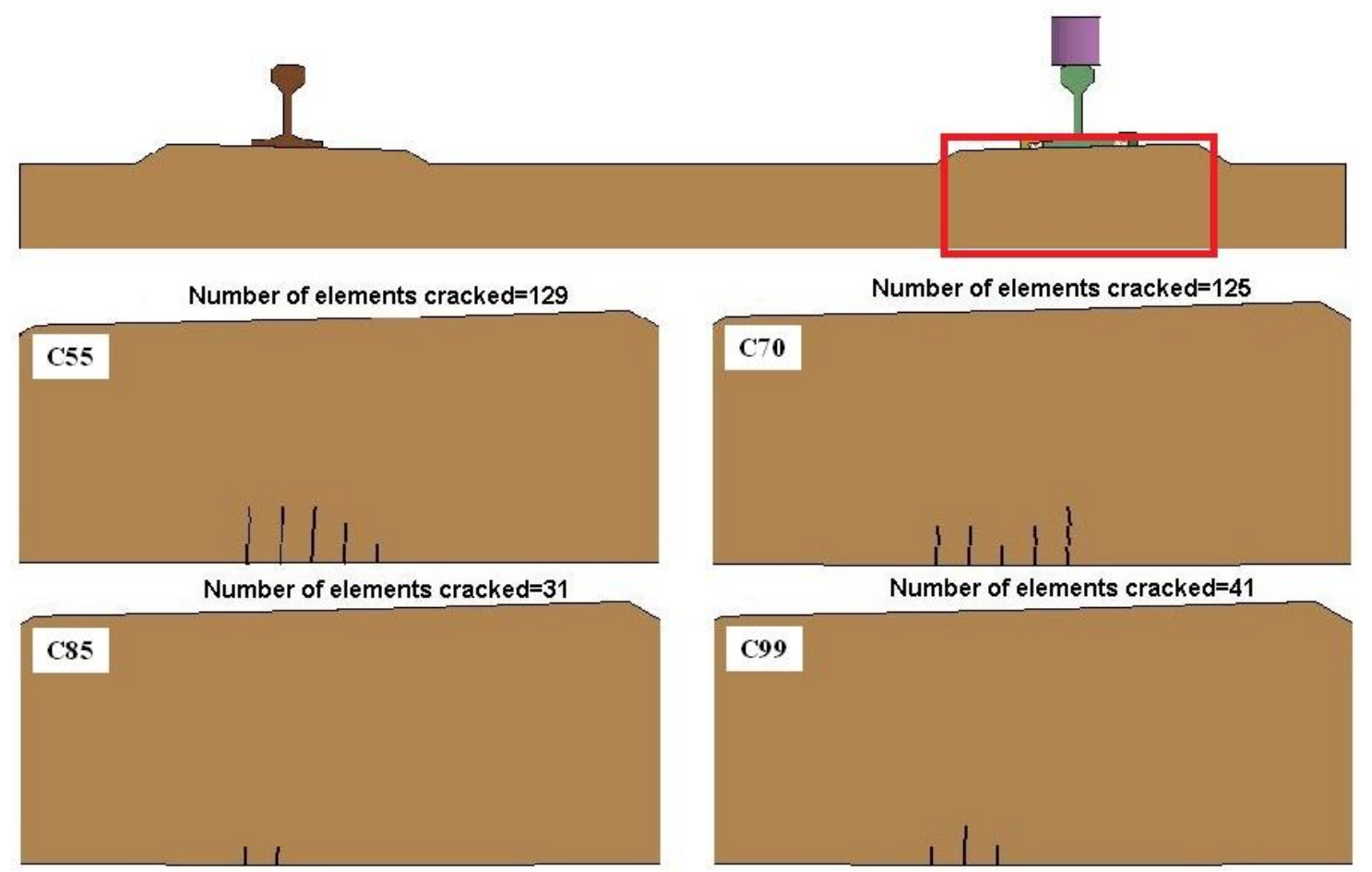

Figure 6 Visible cracks at the bottom of right rail seat due to drop height of $600 \mathrm{~mm}$
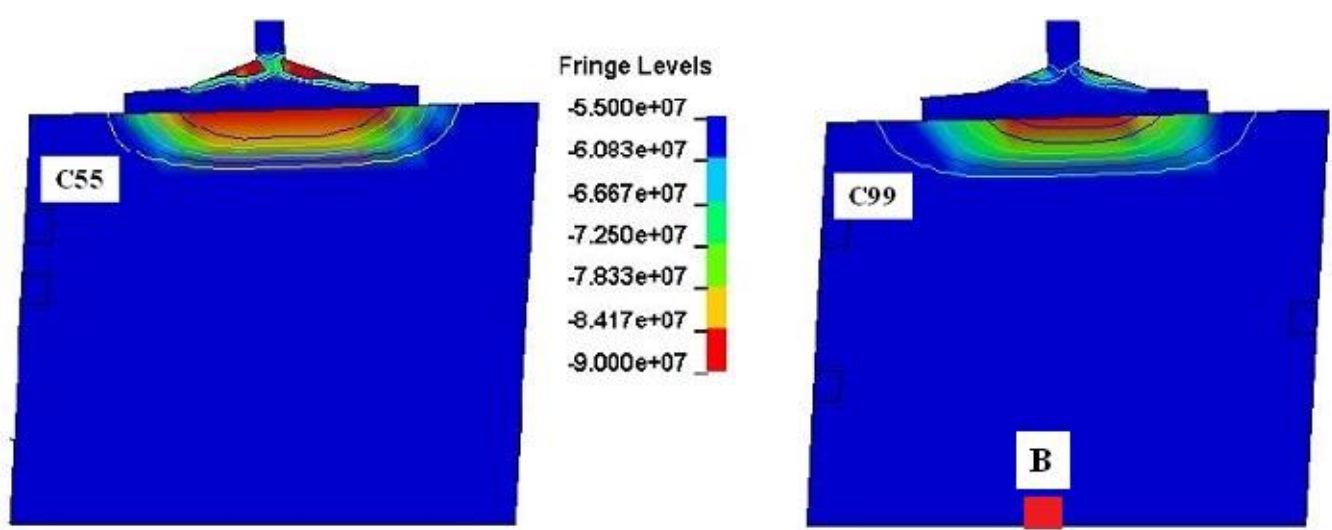

Fringe Levels

$5.500 e+07$

$-6.500 \mathrm{e}+07$

$-7.500 \mathrm{e}+07$

$8.500 e+07$

$-9.500 \mathrm{e}+07$

$-1.050 \mathrm{e}+08$

$-1.150 e+08$

Figure 7 Area of the sleeper compressive stress (Pa) due to drop height of $600 \mathrm{~mm}$

The above results show that using higher grade of concrete as material for PCSs does not necessarily results in a proportional increase of the sleeper load-carrying capacity. The results indicate that using a larger grade of concrete material leads to an increase of bending moment and bending stresses for the same dynamic load generated at the rail head. For example by replacing concrete grade $\mathrm{C} 55$ with concrete grade $\mathrm{C} 70$ the bending moment, compressive stress and tensile stress increase about 5, 14 and 8 percent, respectively, see Table 3. This confirms the inadequacy of current static analysis and allowable-stress design approaches which are accepted by standard codes such as AS-1085.14 (2012).

The next step of the investigation is examining the influence of each key mechanical properties of concrete on behaviour of sleeper. This constitutes work in progress at the University of Melbourne. The Study will provide a deeper insight into the behaviour of high performance concrete sleepers and will support designers to choose the most suitable material properties for PCSs. It is also expected that the investigation contributes to the establishment of a new design approach of PCSs. 


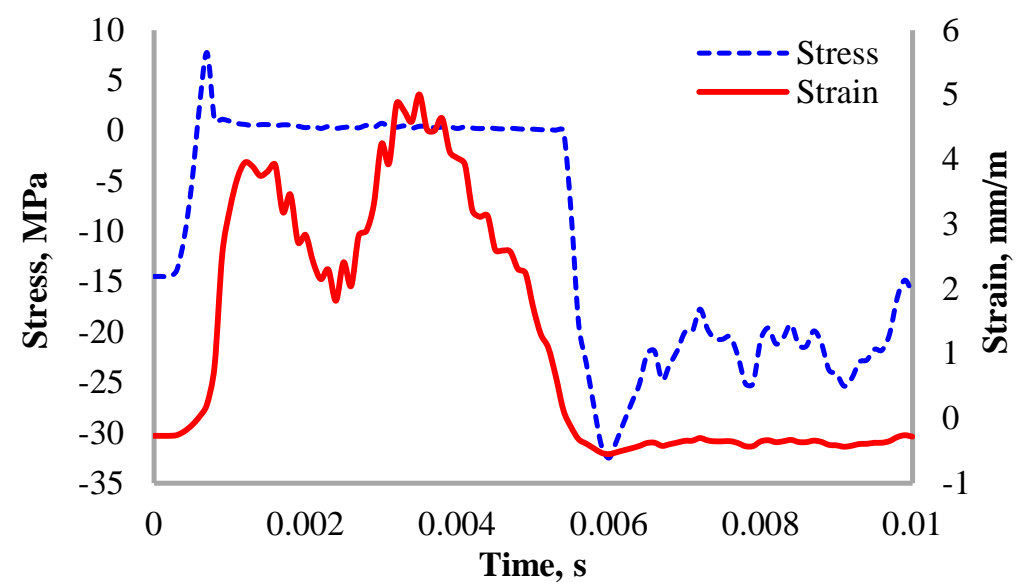

Figure 8 Time history of tensile stress and strain at the bottom of rail seat, concrete grade C99, drop height of $600 \mathrm{~mm}$

\section{CONCLUDING REMARKS}

Using ANSYS LS-DYNA package, a finite element model has been developed to investigate the behaviour of high performance concrete sleeper under dynamic loads. The model has been validated based on results of experimental investigation published in the literature. At first step the behaviour of a sleeper made of different grades of high strength concrete has been studied under a dynamic load of $885 \mathrm{kN}$.

The results shows that using larger grade of HSC does not lead to a proportional increase of sleeper loadcarrying capacity as a result of larger bending moment generated under same dynamic load. This confirms the inadequacy of the current approach of analysis and design of pre-stressed concrete sleepers.

The findings also indicate that the capability of developed finite element model in simulating concrete sleeper subjected to dynamic loads. So, the next step is using the model to investigate the behaviour of high performance concrete sleepers subjected to dynamic loads. It is expected that the investigation provides a deep insight into the behaviour of pre-stressed concrete sleepers which, in turn, can be associated with establishing a new design approach.

\section{REFERENCES}

AS-1085.14. (2012). "Railway track material part 14: prestressed concrete sleepers", Standards Australia Institute.

AS-1085.19-2013. (2003). "Railway track material part 19: resilient fastening assemblies", Standards Australia Institute.

AS-3600. (2009). "Concrete structures australian standard", Standards Australia Institute.

Brannon, R. M., and Leelavanichkul, S. (2009). "Survey of four damage models for concrete", Technical Report, Sandia National Laboratories, Albuquerque, USA.

Cai, Z. (1992). "Modelling of rail track dynamics and wheel/rail interaction", PhD Thesis, Queen's University, Ontario, Canada.

Dong, Z., and Keru, W. (2001). "Fracture properties of high-strength concrete", Journal of Materials in Civil Engineering, 13(Feb.), 86-88.

Hallquist, J. O. (2006). "LS-DYNA theory manual”, Livermore Software Technology Corporation, Livermore, USA.

Hwang, C. L., Chen, C. T., Lee, L. S., Bui, L. A. T., Hou, B. S., and Hsieh, H. Y. (2011). "The material and mechanical property of heavy-duty prestressed concrete sleeper", Applied Mechanics and Materials, 9798, 408-413.

Kaewunruen, S. (2007). "Experimental and numerical studies for evaluating dynamic behaviour of prestressed concrete sleepers subject to severe impact loading", PhD Thesis, University of Wollongong, Wollongong, Australia.

Kaewunruen, S., and Remennikov, A. M. (2008). "Experimental simulation of the railway ballast by resilient materials and its verification by modal testin", Experimental Techniques, 32(4), 29-35. 
Kaewunruen, S., and Remennikov, A. M. (2009). "Progressive failure of prestressed concrete sleepers under multiple high-intensity impact loads", Engineering Structures, 31(10), 2460-2473.

Kaewunruen, S., and Remennikov, A. M. (2010). "Dynamic crack propagations in prestressed concrete sleepers in railway track systems subjected to severe impact loads", Journal of Structural Engineering, 136(6), 749-754.

Kaewunruen, S., and Remennikov, A. M. (2011). "Experiments into impact behaviour of railway prestressed concrete sleepers", Engineering Failure Analysis, 18(8), 2305-2315.

Leong, J. (2007). "Development of a limit state design methodology for railway track", Master of Engineering Thesis, Queensland University of Technology, Queensland, Australia.

Leong, J., and Murray, M. H. (2008). "Probabilistic analysis of train-track vertical impact forces", Proceedings of the ICE - Transport, 161(1), 15-21.

Li, W., Wang, X. C., and Zhang, J. P. (2012). “An overview of the study and application of rubberized portland cement concrete", Advanced Materials Research, 598, 374-378.

LSTC. (2009). "LS-DYNA keyword user's manual (Volume II: Material models)", Livermore Software Technology Corporation (LSTC), California, USA.

Mendis, P. (2001). "Design of high strength concrete members: state-of-the art", Engineers Australia, Sydney, Australia.Mendis, P., Pendyala, R. S., and Setunge, S. (1997). "Requirements for high-strength concrete in as3600", High-performance Concrete sub-committee of the Concrete Institute of Australia (Victoria), Melbourne, Australia.

Mohammadzadeh, S., and Vahabi, E. (2011). "Time-dependent reliability analysis of b70 pre-stressed concrete sleeper subject to deterioration", Engineering Failure Analysis, 18(1), 421-432.

Murray, M. H., and Bian, J. (2012). "Ultimate limit states design of concrete railway sleepers", Proceedings of the Institution of Civil Engineers - Transport, Vol. 165, pp. 215-223).

Nairn, J., and Stevens, N. (2010). "Rational design method for prestressed concrete sleepers", Proceeding of Conference on Railway Engineering (pp. 174-190), Engineers Australia, Wellington, NZ.

Ramezanianpour, A. A., Esmaeili, M., Ghahari, S. A., and Najafi, M. H. (2013). "Laboratory study on the effect of polypropylene fiber on durability, and physical and mechanical characteristic of concrete for application in sleepers", Construction and Building Materials, 44, 411-418.

Remennikov, A. M., and Kaewunruen, S. (2008). "A review of loading conditions for railway track structures due to train and track vertical interaction", Structural Control and Health Monitoring, 15(Oct.), $207-234$.

Remennikov, A. M., Murray, M. H., and Kaewunruen, S. (2007). "Conversion of as1085 . 14 for prestressed concrete sleeepers to limit states design format", Proceeding of AusRAIL PLUS (pp. 1-18), Sydney, Australia.

Schwer, L. (2011). "The winfrith concrete model : beauty or beast? insights into the winfrith concrete model", Proceeding of 8th European LS-DYNA Users Conference. Strasbourg, France.

Steffens, D. M. (2005). "Identification and development of a model of railway track", Master of Engineering Thesis, Queensland University of Technology, Queensland, Australia.

Taherinezhad, J., Mendis, P., and Ngo, T. (2015). "Investigation of three concrete material models of ls-dyna for analysing pre-stressed concrete sleepers", Proceeding of 10th International Congress on Civil Engineering, Tabriz, Iran.

Taherinezhad, J., Sofi, M., Mendis, P., and Ngo, T. (2013). "A review of behaviour of prestressed concrete sleepers", Electronic Journal of Structural Engineering, 13(1:Special Issue), 1-16.

Van Dyk, B. J., Dersch, M. S., and Edwards, J. R. (2012). "International concrete crosstie and fastening system survey - final results", Technical Report, RailTEC, University of Illinois at Urbana-Champaign, Illinois, USA. 


\section{University Library}

\section{- M I I N E R VA \\ A gateway to Melbourne's research publications}

Minerva Access is the Institutional Repository of The University of Melbourne

Author/s:

Javad, T;Mendis, P;NGO, T;Sofi, M

Title:

Behaviour of Pre-Stressed High Strength Concrete Sleepers Subjected To Dynamic Loads

Date:

2015

Citation:

Javad, T., Mendis, P., NGO, T. \& Sofi, M. (2015). Behaviour of Pre-Stressed High Strength Concrete Sleepers Subjected To Dynamic Loads. Fernando, D (Ed.) Teng, J-G (Ed.) Torero, $\mathrm{JL}$ (Ed.) Proceedings of the Second International Conference on Performance-based and Life-cycle Structural Engineering (PLSE 2015), pp.339-347. University of Queensland. https://doi.org/10.14264/uql.2016.942.

Persistent Link:

http://hdl.handle.net/11343/58659 